\title{
The Gate-Resonance
}

Model: The Interface of Policy, Media and the Public in Technology Conflicts

Helge Torgersen Jürgen Hampel 


\title{
The Gate-Resonance Model: The Interface of Policy, Media and the Public in Technology Conflicts
}

\author{
Helge Torgersen*, Jürgen Hampel** \\ * ITA - Institute of Technology Assessment of the Austrian Academy of Science, Vienna, Austria \\ ** Centre for Technology Assessment in Baden Württemberg, Stuttgart, Germany
}

\section{Keywords}

theoretical framework, technology conflict, interest representation, public mobilisation, resources

\begin{abstract}
The gate/resonance model provides an analytical frame for the description of technology conflicts. It offers an analytical scheme to conceptualise the interaction between public opinion, interest representing organisations, the media and the political system. The model distinguishes structural elements, functional elements and processes. Structural elements are the public with sub-publics and representational fields, the regulatory system with its institutions, intermediary organisations representing interests and bridging the gap between the public(s) and the regulatory system, the regulatory space and the media that mirror and participate in interest conflicts. Functional elements are resources, which enable intermediary organisations to convey interests to regulation, and filters that prevent information overflow within regulatory institutions: the gate as a formal function selects information according to statutory criteria, detectors according to usefulness for the institution. Processes described are the movement of issue fields due to re-interpretation; resonance, the tuning-in on issue interpretation among different actors; mobilisation, the generation of political pressure through resonance; and policy change through the abolishment of established interest and actor equilibrium due to mobilisation and ensuing gate failure. The model is applied to the example of biotechnology conflicts.
\end{abstract}

(c) $\mathbf{T} \mathbf{\Delta}$ - Institute of Technology Assessment of the Austrian Academy of Science

A- 1030 Vienna, Strohgasse 45/5, Fax: +43-1-710 9883

http://www.oeaw.ac.at/ital

ISSN $|68|-9 \mid 87$ 


\section{Content}

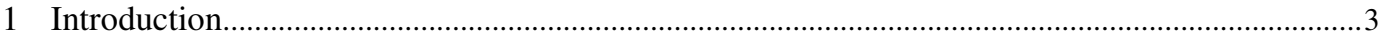

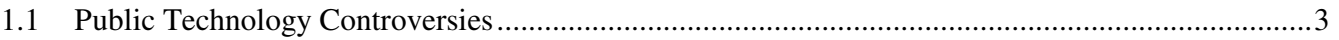

1.2 Conveying Interest and Views in a Pluralistic Society ..........................................................

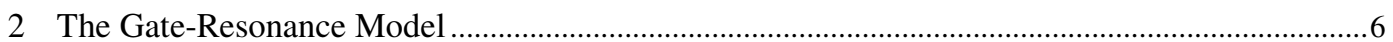

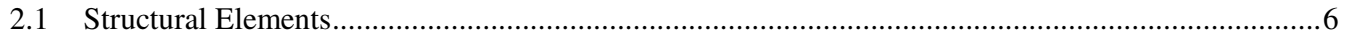

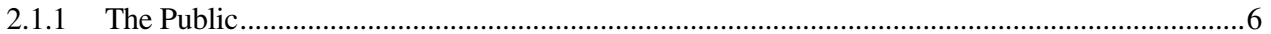

2.1.2 The Regulatory System..................................................................................................

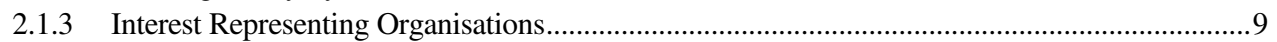

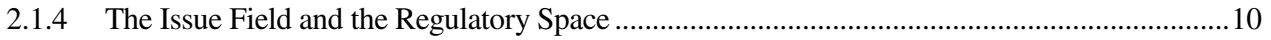

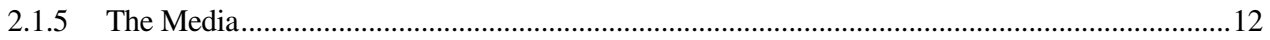

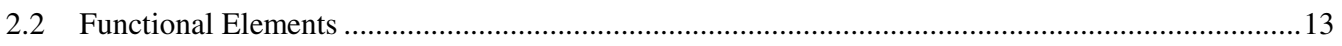

2.2.1 Resources of Intermediary Organisations ........................................................................ 13

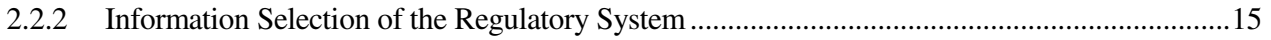

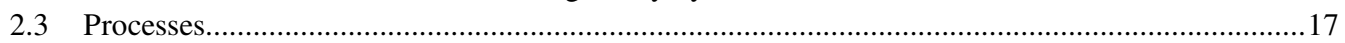

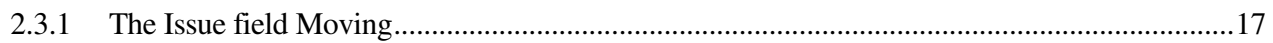

2.3.2 Resonance

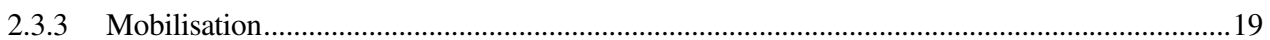

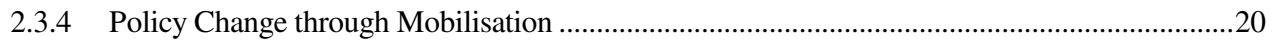

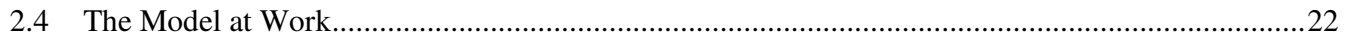

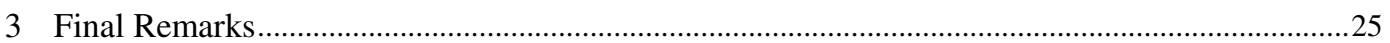

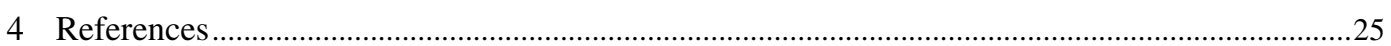




\section{Introduction}

Any issue that is deemed politically relevant is multi-facetted; it consists of various actors" inputs and is shaped by processes in the public where the media play a decisive role. What is considered a politically relevant issue is the result of a highly complex social process. Ideas, concerns and social representations find their way from the public, the media and societal institutions into the regulatory system, where different understandings of what is relevant with an issue influence political decision-making (Renn 1992).

In this paper we propose an analytical frame for describing the relation between relevant societal sub-systems and key actors in technology conflicts. ${ }^{1}$ For the purpose of this paper we focus on the relation between the public, the media and the political system (Gaskell/Bauer 2001), with respect to how ideas, concerns and representations in the public are conveyed to the policy process. ${ }^{2}$ Departing from interest representation in such controversies, it explores structural elements such as the public, the media, the political system, functional elements like resources and filter elements, and processes such as probing, resonance and mobilisation. Rather than to re-conceptualise indepth single relationships between these elements, the gate/resonance-model aims to draw together views from different disciplines and schools.

\section{I.I Public Technology Controversies}

Public controversies over new technologies like genetic engineering or nuclear power had a significant impact on their implementation. Events in the public sphere massively influenced political decisions on the permission, the promotion and the dissemination of contested technologies. One reason for this was the shift from the wide-spread general optimism predominant in the post-war period, assuming that technological progress was a benefit in itself, towards a more critical attitude in parts of the public. In the new frame of technological controversies, the implementation of a new technology became not only a question of progress and future economic well being but also of undesired or deleterious effects. Possible impacts on everyday life elicited questions about the compatibility of technological innovation with the value system of a given society. While in the public debate general issues pertaining to the future and direction of social development were frequently addressed, the regulatory discourse in most western countries centred almost exclusively on questions of risk to human health or the environment (Torgersen/Hampel forthcoming).

In the light of the broad societal debate on culture and technology it is not surprising that discourses over risk have failed to close the debates. Not only did the scientific community and the public disagree about the magnitude of risk, but also about the very concepts of risk (Slovic et al.

1 We are greatly indebted to our many colleagues from the European Commission (DG Research)-funded project 'Life Science in the European Society' (QLRT-1999-00286), especially Martin Bauer, John Durant, Edna Einsiedel, George Gaskell, Andreas Kohring, Franz Seifert and others for encouragement and critical discussion as well as many constructive ideas. We thankfully acknowledge critical reading by Ortwin Renn and Andreas Klinke (Academy for TA Baden Wuerttemberg) as well as Gunther Tichy, Michael Nentwich and Georg Aichholzer (ITA/OEAW).

2 We are aware that the scientific-industrial system as the generator and developer of technology plays a significant role that may exceed that of intermediary organisations as described in the paper. However, for the purpose of describing the relationship between the public, the media and the political system we include actors of the scientific-industrial system and their interests under 'institutionalised interests' (see below). 
1987, Hampel/Renn 2000). Scientific experts attempted to control uncertainty by applying a technical concept (Evers/Nowotny 1987). For members of the public, in contrast, risk was a proxy for an uncertain future. Apart from being conceptually ambiguous in itself, the issue of risk was closely related to value questions, but rarely addressed as such.

Controversies over risk and technology do not arise between 'the' public and 'the' regulatory system. Rather, there are numerous social actors involved. Consequently, such conflicts do not only have a content dimension but are also social processes in which interests get mediated. Industry and scientists, as single actors or through their associations, churches and other organisations promoting certain value systems, trade unions representing the workforce's political and material interests as well as NGOs promoting various issues from environmental or consumer protection to animal rights discuss new technological developments. According to their different interests and world-views, they try to influence the regulation of new technological developments. In the following, we will call this process 'interest representation' and denominate the actors involved as 'intermediary organisations' irrespective of their size and nature. The media closely observe, selectively display and often amplify the arguments and activities of these actors, thus becoming social actors themselves.

The relationship between public opinion, the activities of intermediary organisations and the political system's regulatory activities challenges our understanding of social processes. Since public opinion has a decisive role, which channels other than elections feed public preferences into political decision-making on contested technologies in a democratic society? What is the public, and what are the conditions under which the public becomes relevant to decision-making? How do various societal actors relate to, or instrumentalise, public opinion?

The gate/resonance model was developed in order to conceptualise some aspects of the policy/society interface in technology conflicts. It describes the interactions, through intermediary interest representing organisations as well as the media, between the public and the political system. In so doing, it integrates structure, i. e. the elements and their relationships, and process, i. e. their concerted functioning. Although it focuses on agenda setting, it has implications for decision-making and the implementation of decisions. The model builds on inputs from sociology, social psychology and political science. It is oriented at sociological research questions about power, featuring policy components like problem definition, definition enforcement and solution proposals. ${ }^{3}$

\section{I.2 Conveying Interest and Views in a Pluralistic Society}

Democratic constitutions emphasise the People as the sovereign and Parliament, legitimised through elections, to exercise legislative power. Views differ, though, on the details in representing peoples various interests. Due to limited resources, Parliament performs only part of the debate and decisionmaking. Societies are active in interest representation between elections, too, and administrations have their own interests.

Different approaches such as pluralism, neo-corporatist and policy network theories have analysed how interests are conveyed in democratic decision-making. Pluralism theory looks at opportunities for social interests to get organised and to influence the outcome of the political process. It assumes that the organisation of interests is a societal process, independent from the political system,

3 Our model is confined, for the moment, to an analysis on the level of the national state. Extension to an international level would be possible; however, it would render the representation complicated. 
which only is the addressee of demands. Accordingly, every interest can find its advocate who turns it into a public issue. Interest representing organisations freely compete for the regulatory institutions' attention. Critics hold that the opportunities of individuals to organise depend on their social conditions, which are unequally distributed within society.

Neo-corporatist approaches reject the idea that interest representation can be clearly separated from state action, rather, they emphasise the constitutive role of the state in the organisation of interests (Streeck 1994:12f.). As in pluralism theory, societal conflicts are seen to be reconciled through direct interaction of opposing interests. However, the state has an active role in overseeing the rules and guaranteeing the existence of interest representing organisations or associations privileged by monopolies and even delegated regulatory functions. ${ }^{4}$ The neo-corporatist model helps to understand the interaction in 'classical' conflicts like those between trade unions and employers with few institutions involved. However, it was not designed to conceptualise the emergence of conflicts involving new social movements. In post-industrial societies, interests have differentiated and the number and forms of 'interest associations' have vastly increased so that interest representation and interest mediation has become a problem of increasing complexity. Replacing traditional interest representing organisations in new types of conflicts, NGOs have acquired influence on the political process and play significant roles especially in policy fields with a link to technology.

The state with its differentiated structure offers various targets for interest representation. Regulatory institutions have closer affiliations to some organisations than to others, ${ }^{5}$ and there are links and coalitions between organisations. Frequently, regulatory institutions get dependent on a constant information flow from within such coalitions of actors. In cases where the state depends on external expertise, according to policy network theory (Mayntz 1993), stable policy communities are more likely. In contrast, in new areas where interests have not yet concretised or where there is significant political controversy, more short-lived issue networks emerge. Networks behave much like individual actors or competitors in a market. They pursue their own interests, ${ }^{6}$ while contextual factors deeply influence their role, strategy and success (Scharpf 1993).

Focussing on the relationship between interest representing organisations and regulatory bodies, these approaches emphasise institutions rather than their social background. For example, critics argue that policy network theory does not adequately take into account the influence of political discourse (Atkinson/Coleman 1992), and that it is increasingly difficult in modern societies to determine the boundaries between issues and policy fields and hence between networks.

Extended by the concept of an agora (Nowotny et al. 2001, p.201 ff), the arena model (Renn 1992) emphasises a public sphere, where agenda setting and interest mediation take place. The arena is a political action space where societal issues become politicised and where problems are formulated, decisions taken and regulations implemented in a structured way. According to the arena model, there are different arenas - law, media, politics, the market - to handle conflicts, where only arenaspecific arguments and resources can be applied. Hence, it differentiates between types of arenas and assigns roles to different social actors, political institutions, as well as to the media and the general public as observers. Accordingly, the political system is an arena where actors - politicians, administrations, political parties, interest representing organisations - use their resources to influence the political outcome (see below, 'Resources'). In a given arena, actors cannot use every

4 Examples are the medical associations or the trade unions statutorily involved in solving labour conflicts, as it is the case in Germany.

5 This is the case especially for interest groups in the neo-corporatist mode of interest representation. For example, agricultural departments usually have a close relationship to farmers' association, and less so to environmental groups, while the opposite is the case for many departments of the environment.

6 For example, opposing networks that include both government agencies, scientists, companies and public organisations could be observed in their attempts to influence a particular state's way of handling genetically modified food. 
resource since resources are arena specific and must be compatible. However, there are two processes that compensate for a lack of arena specific resources and that connect actors within and between areas: communication and mobilisation. Actors can modify the arena's rules by interacting with previously uninvolved groups in order to use the optimal set of available resources, and they can increase their resources by mobilising the public.

The arena model offers a framework for understanding policy structures, but it remains somewhat static. It does not analyse the processes between actors conveying interests and views to the decision making process and remains vague with respect to the role of the public. The gate/resonance model attempts to go beyond by describing functionally important aspects of the relationship between the public, the political system and the media. In the following, we will first describe the structural and functional elements before turning to processes which these elements are involved in.

\section{The Gate-Resonance Model}

\section{I Structural Elements}

In a democratic society, all regulatory activities, and the perception thereof, take place in the public space. Within this space, the political system takes regulatory decisions, and the media record, select and display events to a potentially unlimited number of people. Being embedded in the public space, they both act vis-à-vis each other (and other subsystems which we will not deal with here) as well as vis-à-vis the 'general public' as if this was a distinct entity. ${ }^{7}$

\section{I.I The Public}

In academic writing, there are many different understandings of the term 'the public': an aggregation of individuals, a specific audience, the media, or even a synonym for society. In the following, we will understand 'the public' firstly, as an aggregate of individuals and thus, public opinion as determined by what goes on in the minds of people. Secondly, 'the public' is a result of the mental construction of individuals and organisations. In both understandings, the term 'public' is related to what is published in the media, either as a source of information and interpretation or as a perceived mirror of what goes on in the minds of people. Both of these understandings frame the term as dependent upon context and the interpretation of the perceiving actors. Differing concepts of 'the public' do not exist independently, and the policy process is interrelated with both of them.

For analytical reasons, we adopt the concept of a separate general public as opposed to the regulatory system and the media, keeping in mind that this is a theoretical and analytical construct rather than a 'real' social unit. The general public consists of all people within a country that are in principle able to communicate and participate in political matters, although they do not necessarily always do so. For quantitative sociology, the term 'general public' is almost synonymous with public opinion to be measured by surveys. It is the aggregation of what individuals in a given society 'think' about a topic.

7 Like the economy, science, arts, etc., which, for the most part, will not be dealt with here. 
Within the general public, there are numerous 'specific' publics. Individuals have unequal cognition, build up different mental representations, hold various world-views and pursue a variety of interests. Accordingly, they form subgroups within the general public. 'Specific' publics are characterised by determined (and often material) interests connected to particular issues, like farmers, commuters, retired people, etc. Overlapping, but conceptually apart, there are groups that are characterised by shared world-views like religious beliefs, political ideologies, etc. Others hold particular opinions about specific or inter-related issues. ${ }^{8}$ 'Representational fields' are parts of the public that share a set of social representations and images of an issue, especially if this issue is difficult to reconcile with the 'Lebenswelt' of a lay person (Wagner/Kronberger, 2001). Such fields are often, but not necessarily, linked to groups holding a general world view or specific publics sharing concrete interests.

Representations, views and interests determine empirically identifiable attitudes. Individuals do not only belong to one but to a multitude of specific publics and representational fields. Hence, 'the public' is like a cloth with multiple layers of overlapping patches of various sizes, colours and categories.

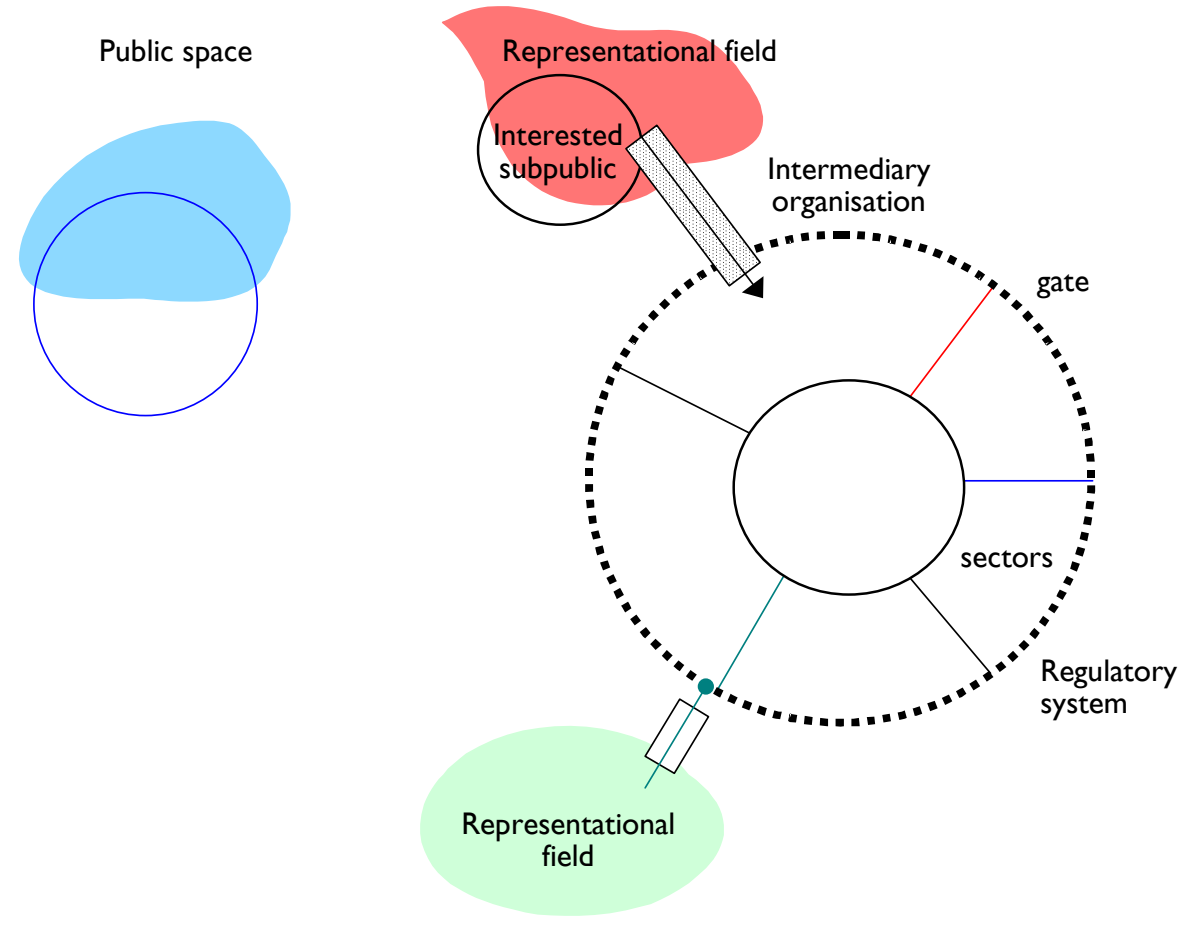

Fig. 1: Public, Regulatory System and Intermediary Organisations

8 Like biotechnology or food issues. 


\section{I.2 The Regulatory System}

Luhmann's systems theory suggests that the political system is not the central unit controlling each subsystem of a society but a subsystem among others with no predominance over them (Luhmann 2000).

In our model, the political system comprises of the regulatory system proper and a surrounding 'halo' of intermediary organisations representing the various interests of specific publics and different views from representational fields. Political parties are a special sub-set of such organisations, representing differing combinations of interests under the umbrella of an ideology. Their role is to establish a direct link between the regulatory system and the public and so they are usually at the centre of analyses of the political system; however, in our model we do not particularly focus on them, as well as on the role of Parliament.

The regulatory system consists of Parliament and the government with its body of administration. Regulatory institutions (like government departments), together with Parliament, regulate different aspects of life according to policy sectors, like industry, agriculture or the environment. ${ }^{9}$ The organisational structure of an administrative bureaucracy ${ }^{10}$ is a result of the basic needs of the political system and its coping with past regulatory demands. Its structure reflects the 'frozen' experience of conflicts within a society. The neo-corporatist approach (Streeck 1994) suggests that adoption processes go back and forth: political institutions play a decisive role in the formation of interest associations and existing associations induce the development of governmental institutions.

Regulatory institutions work together in establishing rules while competing for competencies - not only interest representatives but also regulators have their particular interests, which may collide within one government (Mayntz 1993). Regulatory institutions thus are not only (more or less passive) addressees of interest representation but important and autonomous actors shaping policy contents according to their own interests and views.

In order to fulfil a regulatory institution's tasks and to sustain its institutional autonomy, sufficient and adequate information about social, political and scientific developments is a basic requirement. To this end, any institution actively observes the environment for developments that either would jeopardise its autonomy, and perceived legitimisation, or that would make it easier to do its work. While some developments would have to be counteracted, others would have to be supported and exploited from early on, making use of synergies between a development and the institution's culture. The rationale behind is to prevent competing regulatory institutions to gain more influence and to increase the respective institution's share of power.

9 Due to its cross-sectional characteristic, biotechnology affects several of them.

10 As well as the internal structure of political parties. 


\section{I.3 Interest Representing Organisations}

Interest representation is a part of the political process. ${ }^{11}$ Intermediary organisations representing the interests of specific publics bridge the gap between the publics and the regulatory system and compete for influence on regulatory activities. Irrespective of their ideology and structure, intermediary organisations are political actors with socially determined values and interests. ${ }^{12}$ They depend on the trust of one or several specific publics with shared worldviews and on their ability to mobilise their members. ${ }^{13}$ They transport specific interests as well as conceptions about issues, or the world in general, held by representational fields into receptive regulatory institutions. Such conceptions act as a 'glue' between like-minded actors sharing interests and supporting each other to influence policy.

The opportunities for interest representing intermediary organisations to be heard are not equally distributed. Regulatory institutions prefer to listen to those organisations that have proven to be either a potential threat for the proper working of the institution, or to be particularly helpful in performing the institution's tasks. If such a relation has been in place for a long time, these interests have acquired the status of being established, and the organisation representing them becomes institutionalised. This is the type of organisation the neo-corporatist approach deals with. Such interests and the organisations representing them usually have access to regulatory institutions. ${ }^{14}$ They can rely on established channels, either constitutional ${ }^{15}$ or through habit ${ }^{16}$. Examples are industry and farmers" organisations or trade unions (Streeck 1994). The more an interest representing organisation is able to control important societal resources and build up pressure, the more likely it is that such an organisation will become institutionalised.

Other interests lack direct access to the regulatory system. For example, interests that have only recently become visible, or those with a lower conflict potential or less abundant resources, often do not easily find admission to regulatory institutions and escape from their attention as they do not correspond with established policy structures. ${ }^{17}$ Organisations that represent them evidently must

11 Although in the following we concentrate on interest representation through distinct intermediary organisations, we are aware of the fact that interests are not necessarily always mediated through associations. Rather, a whole societal subsystem may act as its own intermediary organisation, as is often the case with the science and technology community in technology conflicts. Also, individual actors may directly exert influence on the regulatory system like with some companies' direct lobbying activities, or they have personal contacts to politicians, like distinguished scientists sometimes do. For our purpose, however, we reduce the variety of ways to convey interests and conceive direct lobbying and mediated representation as functionally equivalent.

12 For example, environmental NGOs often adopt a conception of nature that cultural theory would call 'precarious' (Douglas/Wildavsky 1982), while business representing institutions tend to see nature to be more 'robust'.

13 Originally, political parties served a similar function. In modern societies, however, both left- or right-wing mass parties have to occupy the broad political centre, which entails that political programs get fuzzy and strategies to personalise politics are taken up to meet the demand of the media. It is therefore increasingly difficult to establish tight links between specific publics and a particular party. Even single-issue parties like the Greens increasingly face the necessity to broaden their agenda and to follow the same rationale.

14 According to the respective countries' political traditions, this may take on different forms. In most countries, institutionalised interest representation is involved in the preparation and formulation of political regulations within the competent bureaucracy. Examples are farmers' associations that constantly negotiate with the departments of agriculture

15 Like co-optation of certain organisations during law making.

16 For example in the choice of expert advice.

17 There are also differences within both types of organisations. For example, there can be differences in the level of formalisation and institutionalisation as well as with respect to their internal structure. For our purpose, however, it is sufficient to deal with organisations as 'black boxes'. 
follow different strategies to convey their topic to the regulatory system. Environmental NGOs for example organise and exert influence through other less formalised ways. ${ }^{18}$

Organisations differ in their proximity to political or to administrative institutions, to the government or to opposition parties. With a change in government ${ }^{19}$, the relative influence of an organisation will grow or fall. The bureaucracy's choice of affiliation with interest representing organisations reflects the respective government's perception on which interests and issues are important or legitimate. It is in the interest of any government to include those interests it deems important and exclude those viewed as detrimental to its aims. Institutionalised interest representation, however, is more robust and less dependent on the sympathy of the political mainstream within the regulatory system.

\section{I.4 The Issue Field and the Regulatory Space}

While the political system reflects the institutional setting of the policy process, the regulatory space reflects the content dimension. A policy issue is a conglomerate of related aspects or items covering a larger field rather than a neatly defined entity. It is the result of the perceptions and interests of a variety of actors, interests and representations projected above each other. Such an issue field has blurred boundaries - there is never unanimous agreement as to whether a policy item belongs to one issue field or to another or to both. This is subject to a definition contest among different parts of society and various regulatory sectors.

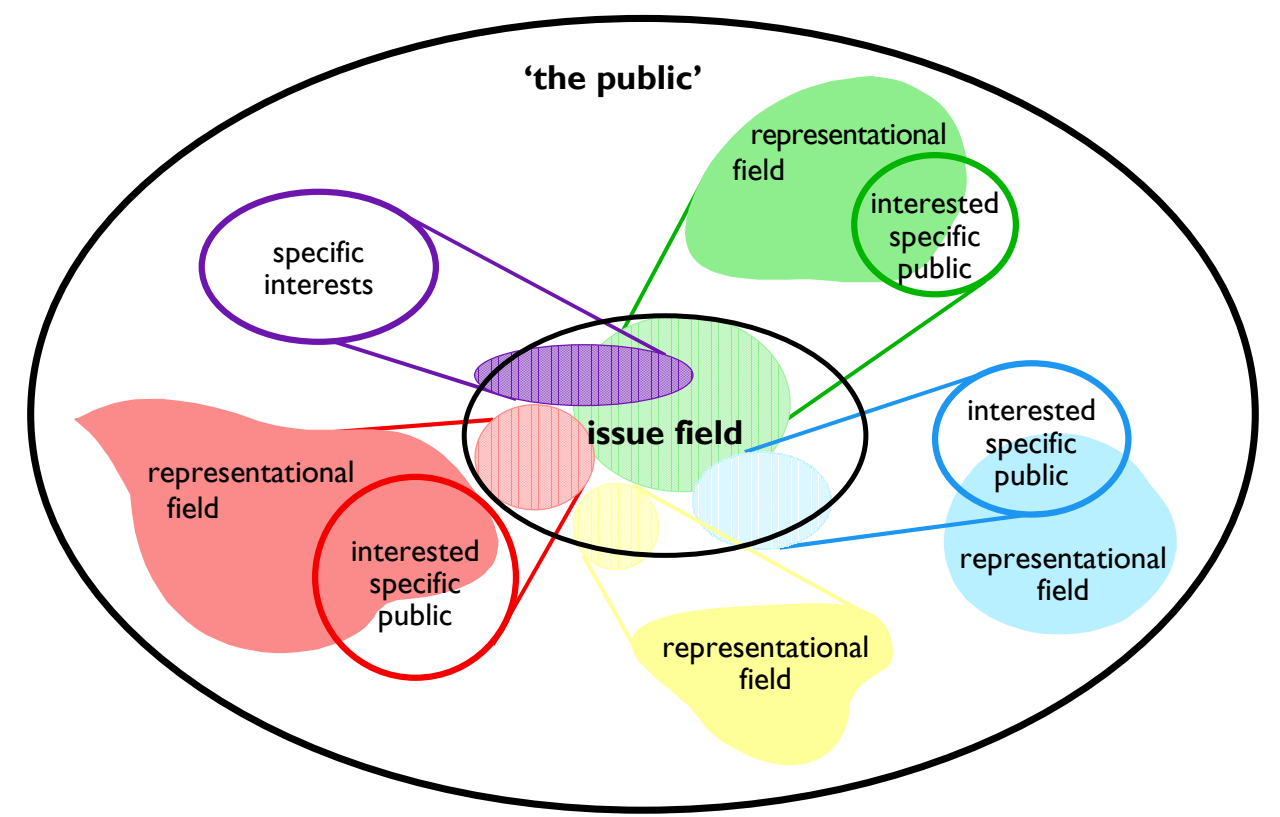

Fig. 2: The Issue Field

18 Although recently in some countries also NGOs have become tightly involved in official governmental policy activities.

19 As it happened in the late Nineties in France, Germany or Austria. 
If the political system decides to regulate the field, institutions engage in negotiations with each other as well as various actors and intermediary organisations. Eventually, they create a regulatory space that covers large parts of, but not the entire, issue field. The regulatory space reflects polity structures like the boundaries of government departments, but also the influence of various interests and their organisations, which compete to influence regulatory decisions. Often intermediary institutions take up aspects coinciding with other interests they represent, not necessarily following the borders of the regulatory space. For example, they don't confine themselves to environmental, agricultural, or industrial aspects as defined by regulators. Rather, they establish channels to different regulatory institutions and become partners for the regulators through expert networking across policy fields.

Usually, established interests conveyed through institutionalised organisations are dominant. They link new issues to issues they have previously covered, so that their interpretation of the new issues according to specific interests acquires legitimisation from previously accepted interpretations. While the system of established interests is reflective of past societal conflicts, new conflicts continually emerge, gain importance and eventually appear on the political agenda. However, the structure of the regulatory system as well as the pattern of established interests, and the coalition between regulatory institutions and organisations representing them, stabilises the preoccupation of policy with conflicts of the past.

Over time, it becomes ever more difficult to reconcile established interpretations with newly emerged ones, and this leads to traditional interests and systems of regulation to be questioned. Additionally, interests represented by intermediary organisations active in several overlapping fields challenge the legitimisation of interpretations by redefining the boundaries of an issue. Finally, often newly founded organisations without access to regulatory institutions take up 'orphan' interests from outside the regulatory space and try to put them on the political agenda. All this contributes to question the boundaries of the regulatory space as well as to fill it with content.

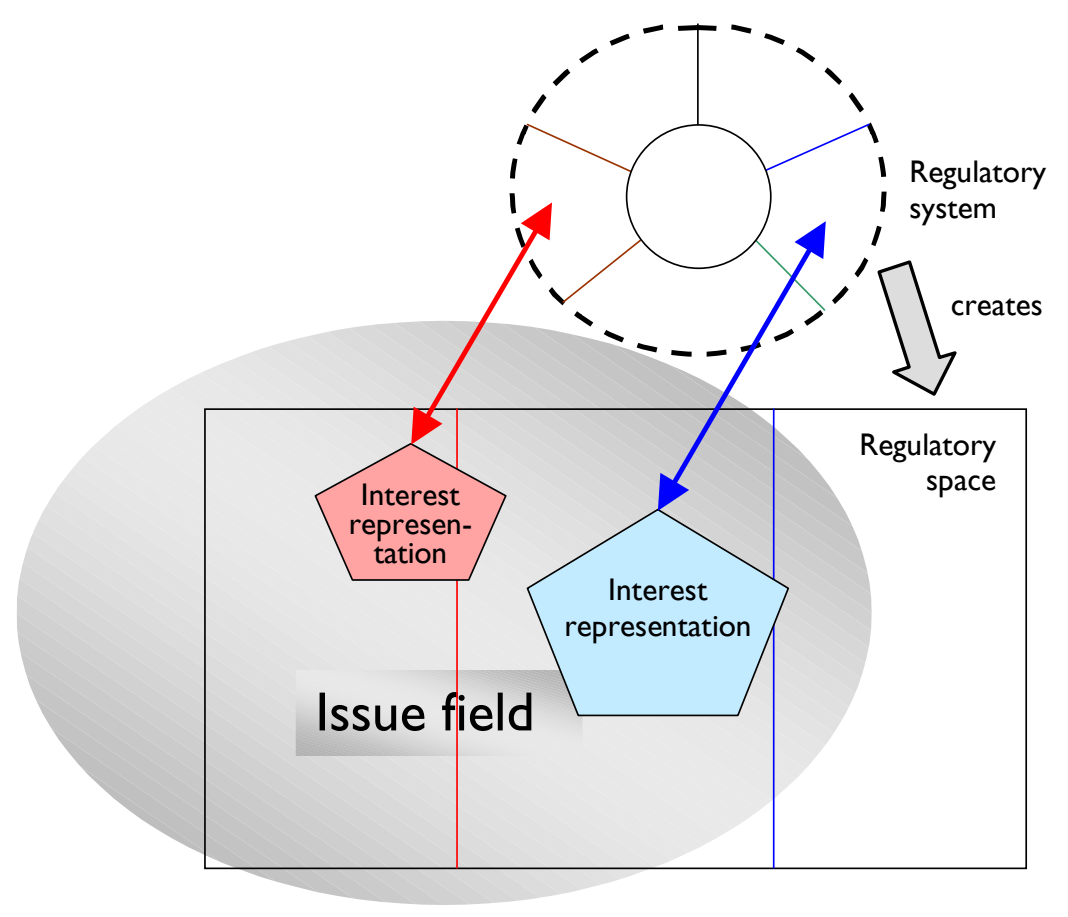

Fig. 3: The Regulatory Space 


\section{I.5 The Media}

The media observe what goes on within policy, within the public and among the interest representing intermediary organisations, and all observe the media. Media determine, to a large extent, what is 'public', i. e. what a wider public in principle can know about an issue. By selecting, reporting and commenting what actors do and say, they define topics of high salience and transport views and interests inextricably linked with information about facts. The linking of background and interpretation is particularly important with complex issues where expert knowledge is important to understand the basics of the topic.

Political institutions keep an eye on media reporting because, between elections, it indicates their position within politics. Since regulatory institutions compete over competencies, it is vital for them to survey, via the media, 'their' interest representing organisations as well as the public. Consequently, activities and arguments covered by the media have a better chance to be considered relevant by regulatory institutions. In this way, the media influence the political agenda setting (McCambs/Shaw 1977:77).

The media are not homogenous. ${ }^{20}$ Apart from differences pertaining to their style and method of communication, they address different publics and thereby play different roles (Bauer et al. 2001). Even within a newspaper, for example, there are sections covering politics, business, science, diary, etc. These sections are relevant to different publics and parts of the political system; the same issue covered in another section conveys a different message. Additionally, importance depends on the sequence and the space or time provided for an issue. The general policy section is usually the most important part and widely recognised by the political system.

Media recipients are more autonomous than is assumed in simple stimulus-response models (Schenk 1987). They are actively selecting, processing and commenting media reports (Peters 2000). Media not only influence their audience but also live from the willingness of their consumers to actively accept the media's choice of information ${ }^{21}$ and the way it is presented. ${ }^{22}$ In fact, apart from their information sources, ${ }^{23}$ media depend mostly on their consumers, as highlighted by the importance for television channels to view quotas and for newspaper to count circulation figures. Thus, the media have to keep in contact with what they perceive to be public opinion while actively shaping it. They are not independent actors dominating public debates but akin to intermediary and political institutions: they are entrepreneurs presenting a product that aims to fit consumer preferences while trying to make preferences fit their supply.

${ }^{20}$ For example, the press can be divided into tabloids and quality papers; there are dailies and weeklies as well as outlets for the general and for specific publics. Each of them has different working conditions and constraints. Television is subject to different rules compared to radio broadcasts, and differences according to country and language can be profound. Furthermore, what media 'really' are becomes more and more obscure. New media like the Internet join the more classical categories newspapers and broadcasting. Classical media, despite their different ways of distribution, have in common that they select, prepare, comment and transport information. The new media differ fundamentally as the media user him- or herself performs these functions. This is the reason why we restrict our analyses to the more classical forms, even if we have in mind that new media will allow establishing new channels of information especially between interest groups and specific publics.

21 To increase circulation, especially tabloids have to find issues that are generally attractive.

22 They have specific rules to select information: personal, direct, concrete, short term and visible messages are preferred over abstract, impersonal, long term and invisible ones.

23 A recent study (Schenk/Sonje 2000) shows that the main information's source for journalists writing on biotechnology are scientists. 


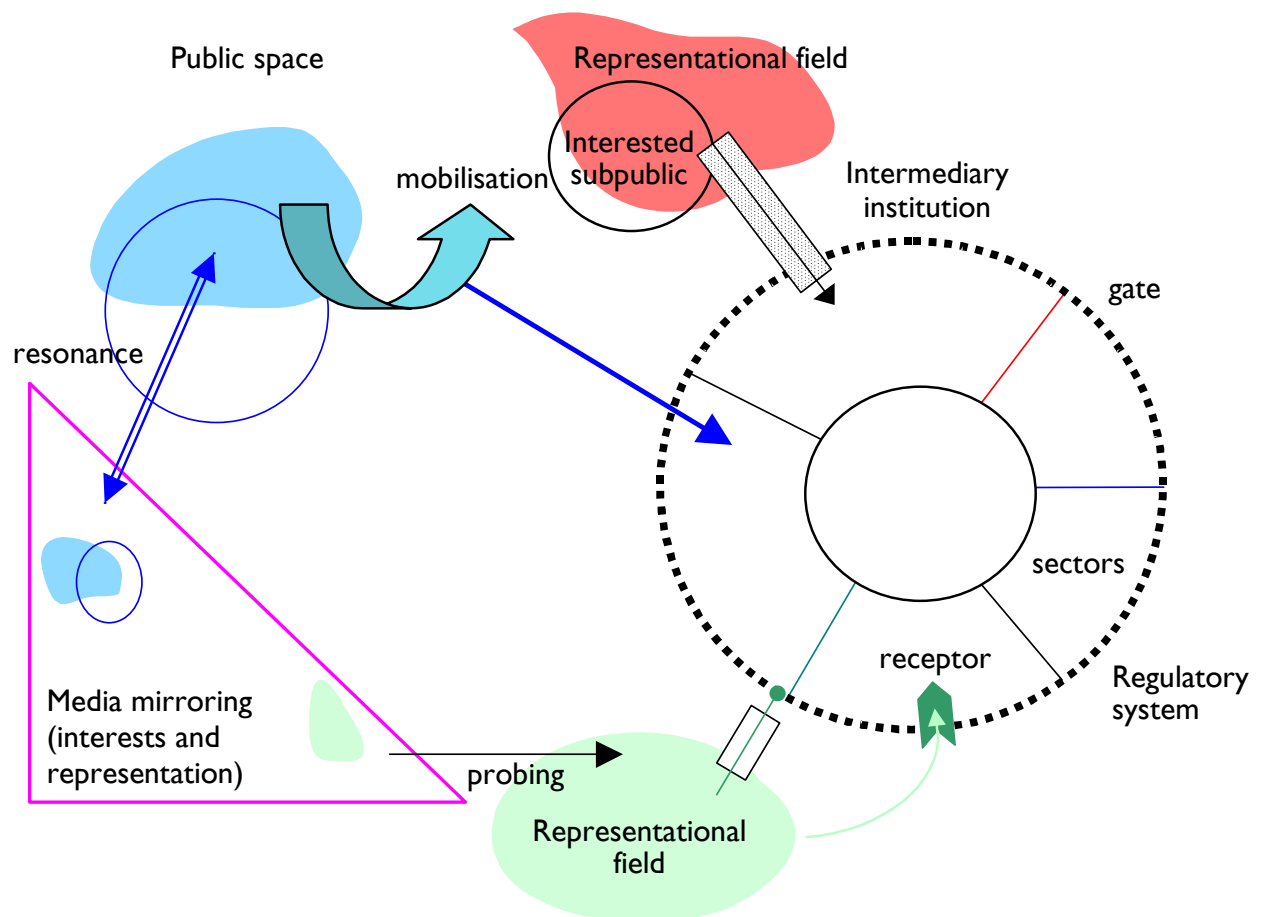

Fig. 4: The Media, Resonance and Mobilisation

\subsection{Functional Elements}

\subsection{Resources of Intermediary Organisations}

According to the arena model, interest representing organisations use their resources in order to convey interests and views to the regulatory system (Renn 1992). There are different kinds of resources, like money, power through de-facto access to decision-making, value commitment, evidence or legitimisation. Financial resources and formal access reflect the organisational strengths of an intermediary organisation. Value commitment is a glue that binds otherwise diverging interests together, especially in technology conflicts where evidence and legitimisation are paramount. In the political arena, money is not officially permitted as a resource. Rather, evidence and legitimisation are the dominant resources, and other types of resources become valuable only if they can be transformed.

Support from scientific evidence is an important and, at times, the only legitimate resource both for an organisation vis-à-vis a regulatory body as well as for the regulatory body in defence of its decision. In a traditional understanding, science delivers facts as a basis for decision-making. If questions arise, scientists are asked to tell the truth independently of their opinions. In a contrasting interpretation, science has a role already in agenda setting by defining the legitimate questions (Millstone et al. forthcoming) Legitimised by their expertise, scientists set up a grid through which potential questions must pass. Arguments get rejected on the basis that they are not scientifically relevant. ${ }^{24}$

24 For example as a hazard of a certain magnitude and probability. As this is difficult to establish with a new technology, one has to rely on comparisons with older, established technologies. Whether this is legitimate or not is a matter of additional dispute. 
Thus, scientists have a double role: they are arbiters committed to factual truth, and they are stakeholders trying to influence the agenda according to their interests and views. ${ }^{25}$ Since it became obvious that science cannot completely reduce uncertainty and new findings always create new questions, scientific evidence has lost part of its resource value in post-modern societies (Wynne 2001). Additionally, there are many scientific communities and often there are several contradicting scientific answers to a regulatory problem. Particularly in new issue fields, interest representing organisations and regulatory institutions privilege one perspective over the other according to their interests. As a consequence, the ensuing dispute questions the credibility of the particular evidence.

Legitimisation is another resource that is most powerful in democratic societies. It is linked to other resources but still separate as it can be derived from various sources like scientific evidence, formal rules (Luhmann 1997), integration in the political system and, most important, public support (Renn 1994). Apart from statutory legitimisation following formal (or legal) rules, political legitimisation is directly assigned through votes in an election or a referendum, ${ }^{26}$ and indirectly by opinion polls indicating that the public supports a particular view. Alternatively, organisations can actively acquire legitimisation in the public through their way of action. Legitimisation can be symbolic through the backing by acknowledged individuals like experts or by reputable institutions, and it is also subject to construction; for example, the reputation of an institution may be derived from political actors stating that it is highly reputable indeed.

Resources are not equally distributed: organisations differ, for example, according to their financial resources to support their operative structure and their ability to influence decisions. As already mentioned, institutionalised intermediary organisations have privileged access to the regulatory system; they are integrated in formal decision-making processes and can mobilise important strategic resources. However, they may lack other types of resources. For example, organisations representing industry interests usually have a high conflict potential and direct links to regulatory institutions. They have access to scientific expertise, but usually enjoy little public support. ${ }^{27}$

In contrast, organised interest representation for example through NGOs has only limited capacity to leverage legitimisation based on institutional reputation or scientific expertise. Neither can most NGOs command important amounts of money nor do they have well-established links to the regulatory system. ${ }^{28}$ Nevertheless, NGOs are influential. More than on money, scientific reputation or channels to the mighty they depend on 'active' legitimisation based on their performance in the public. Especially if they are not institutionalised, most intermediary organisations can greatly increase their legitimisation if they succeed to attract support from a wider public. In order to do so, their rationales need to be in tune with attitudes that are widely distributed in the public.

25 For the relation between science and decision making, see Sheila Jasanoff's book 'The Fifth Branch' (Jasanoff 1990).

26 Another key factor is the sheer number of members of an organisation. Professional associations, for example, derive much of their legitimisation from the percentage of professionals represented by the organisation or by the turnout in internal ballots.

27 Also industry organisations can claim public support by addressing topics of economic competition and unemployment.

28 The establishment of environmental and consumer protection ministries in national governments and respective DGs in the European Commission provide a chance for NGOs to establish direct links to governmental structures. 


\subsubsection{Information Selection of the Regulatory System}

On any given issue, theoretically there is an unlimited amount of information. However, like any institution, regulatory bodies can only process limited amounts. To prohibit information overflow, the regulatory system is open for some but not for all interventions from the public or from intermediary organisations, it accepts only certain kinds of information and is open only to certain organisations and experts for advice and influence. The problem arises how to select the relevant bits of information from those that are irrelevant or even deleterious. Our model suggests that any regulatory institution has two different filter functions that select the issues it will deal with.

\section{The Gate}

A formal function we call the 'gate' selects information according to formal and openly declared criteria. Such information can easily be processed, for example, through established and formalised routines.

The gate is the central filter element in the regulatory system's normal mode of processing different interests. ${ }^{29}$ Information has to pertain to an aspect officially declared to be legitimate for the particular institution. This formal requirement serves to reject any argument not following a certain rationale. If an actor's input is about something that is not relevant as defined by the gate, the input is obsolete. Conversely, arguments get accepted and pass the gate if they are compatible with the statutorily demanded scope.

What the gate really 'is' varies over time and is the outcome of a political process. For example, it can be a decree that only a certain aspect of an issue, like physical risk, is considered legitimate, or an institutional set-up that allows only certain organisations to comment on an issue. The gate is a functional entity, be it an institution or a formal procedure or a combination of both that follows explicit rules. The gate represents a regulatory institution's official interface for the outside world.

The function of the gate to select issues and to prevent information overflow within the regulatory institution can be put out of order by flooding the gate above a threshold level. With pressure increasing, arguments may get through (or rather, over) that would normally not have passed the gate. Thus, input from new actors may, rather haphazardly, reach the regulatory system, but only if the issue is highly salient and if there is considerable lobbying activity or public pressure. The concept of the gate suggests exclusion and conceptualises those parts of the political process where the public and the representation of particular interests are active and the regulatory system passive.

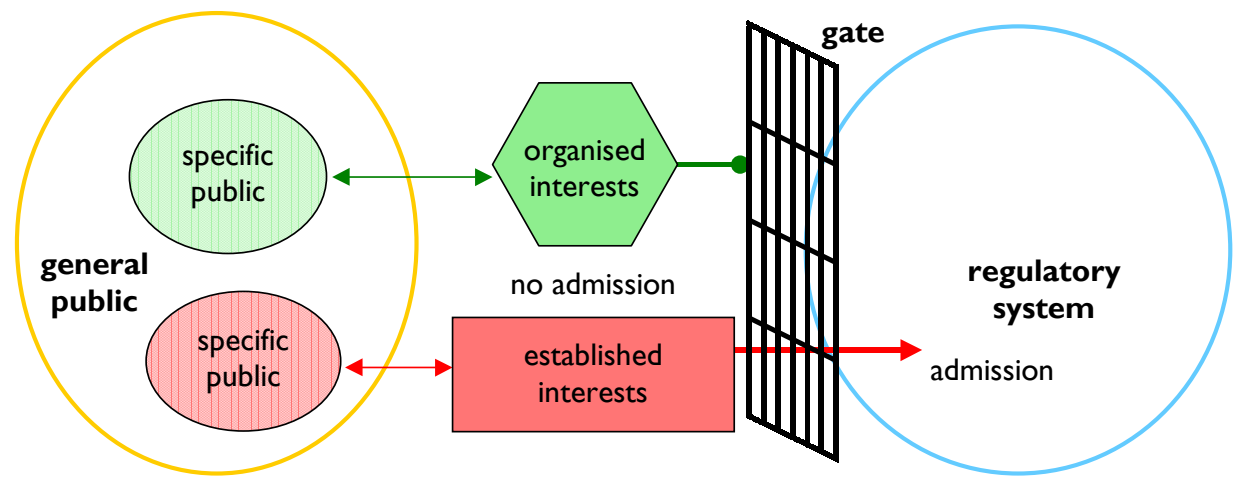

Fig. 5: The Gate

29 see endnote 19 


\section{The Detector}

Information flow through the gate is not sufficient to avoid or deal with new conflicts. Like interest representing organisations and the media, regulatory institutions actively observe their environment. In addition to formal selection through the gate, an informal function we call 'detector' actively selects information from the environment according to whether it is either useful for the institution's normal functioning or threatens its autonomy.

Detectors actively take up information 'through the back-door' in order to respond to societal developments. They are, for example, persons within an institution who scan the media and whose task it is to keep an eye on political, scientific or societal developments and assess them for their potential impact on the institution. Apart from special personnel, detector functions are inherent in the procedural information processing mechanisms, in the personal biases of leading employees as part of their corporate identity, in informal links to intermediary organisations, other regulatory institutions and the media, and in many other forms.

Although this function is independent of the gate and does not comply with its formal rules, there are criteria, too, though mostly informal. Apart from being relevant for running the institution's jobs, information taken up must be compatible with the main institutional bias; if it is too challenging it gets rejected. Information should also contribute to avoid hazards for and increase the institution's autonomy. Uptake specificity thus mirrors the institution's tasks, organisational elements and structural linking as a result of its experiences in past conflicts.

Seen from within an institution, the function of a detector is to selectively gather information. Seen from outside, this function provides the opportunity for arguments and interests to gain access if only the right information is presented. Hence, the detector is also a receptor for information presented from outside that would not pass the regulatory gate. Interest representing organisations use this in order to promote 'non-canonical' arguments and to bypass the gate.

\section{The Relation Between Gate and Detector}

The difference between gate and detector access is related to that of institutionalised and organised interests. While the gate is the official entrance for arguments and interests to the regulatory system, detectors open a side-way to those institutions whose bias is more compatible with the views and interests of a particular interest representing intermediary organisation. The relationship between information flow through the gate and through detectors also reflects the difference between administration and politics. While administration is tied to formal rules and is highly (though not exclusively) gate determined, politics depend more on informal information. The gate supports continuity, the informal uptake through detectors provides for institutional learning.

The selection processes of the gate and of receptors are not mutually exclusive; rather, they may be successive steps in a decision making process. For example, candidates for a job within an institution are selected according to formal requirements like testimonies and education grades. From the pool of suitable candidates, informal criteria (through detectors) may bring about the final decision to choose a particular person. It becomes clear that detector action is the basis for the success of lobbying and 'old boy' networking.

Continuous access through detectors of arguments and interests being incompatible with the gate"s criteria may lead, in the long run, to a change in the selectivity of the gate. Provided detector action is substantial, a discrepancy may arise between arguments and interests that get factual access to regulatory institution and the criteria of the gate. Institutional learning would then amend the latter in order to reconcile the arguments and interests that acquire access, on the one hand, and, on the other hand, the gate criteria. 
Since individuals play an important role in defining detector specificity, detector selection is a chance for dedicated individuals to influence the institutional bias. There is ample evidence, especially from cases of contested technologies, that civil servants " personal views initially being at odds with the overall institutional bias were able to change the whole institutions policy in the long run by allowing formerly 'forbidden' arguments to enter into regulatory decision-making (Torgersen/Seifert 2000).

\subsection{Processes}

\subsection{The Issue field Moving}

For a certain constellation of interests and problems, i. e. for a certain time period, regulatory coverage of the issue field may be sufficient. The regulatory system functions in a 'normal' mode considered to adequately deal with upcoming problems. However, although ever more detailed regulations populate the regulatory space over time, they increasingly fail to cover the issue field. Due to scientific, social or economic changes, the issue field moves, i. e. its most relevant societal definition changes over time. Hence, the field slowly moves within, and eventually out of, the regulatory space by a process of issue erosion, on one hand, and extension on the other ${ }^{30}$. At the end, some parts of the regulatory space will become obsolete, while other aspects, which have not yet received regulatory attention, will not be covered at all.

Some institutionalised organisations with rigid ties to regulatory institutions will not be able to follow the move of the issue field as they cling to their established definitions, and a re-definition would render their agenda less urgent and diminish their importance. The moving issue field may reach new organisations representing new interests. Such newcomers rarely have important material resources or established channels to regulatory institutions.

Regulatory institutions aim to defend their autonomy and maintain the status quo. Newcomer organisations threaten to distort the delicate balance between different established interests and thereby jeopardise regulatory autonomy. In order to avoid any imbalance and re-distribution of influence, regulatory institutions often try to gain time. They delay decisions by freezing activities in a contested field or establish committees to discuss the problem at length.

As part of a long-term strategy to extend their influence over a newly shaped issue field, regulatory institutions also pro-actively invent new regulations to guide the field in the 'desired' direction. Regulation, among other tasks, serves to neutralise the activity of new interest representing intermediary organisations that may have arrived within the reach of the issue field and, in effect, prevent the balance of power among reliable partners from being disturbed. Alternatively, regulatory institutions may disarm newly arrived intermediary organisations through co-optation and the active shaping of new networks under the firm control of the institution.

Widening the regulatory space increases the power of an institution and allows formal legitimisation to grow. Attempts to extend power, however, do not go undisputed. Institutions must defend themselves against antagonising regulatory bodies that compete for power and competencies. If in fear of a loss of influence, institutionalised intermediary organisations representing established interests may use their links to regulatory institutions in order to prevent a change in the status quo.

30 Through technological innovation, which renders some safety regulations outdated, as well as through a constant re-definition of the problems that have to be dealt with. 


\subsubsection{Resonance}

In post-industrial modern societies, regulatory structures and policy formation involving established coalitions of actors have often become quite stable if not petrified. When the issue field moves, traditional means of interest representation through established organisations and networks become insufficient. In order to bring in new aspects, actors and interests reflecting a rapidly and profoundly changing society alternative means are required. One such means is mobilisation and, as a precondition for mobilisation, resonance between (certain) intermediary institutions and (parts of) the public. However, not every intermediary organisation is equally able to elicit, or dependent on, such a resonance.

Intermediary organisations representing interests differ in their resources, particularly in their access to regulatory institutions. Institutionalised intermediary organisations have direct access; their particular input according to established interests is likely to be received through open gates or selectively taken up by regulatory institutions' detectors. Organisations that lack direct access and represent non-established interests must apply other resources to introduce their input to the regulatory system. A main resource for such organisations is legitimisation by the public, and in order to achieve legitimisation, they depend on 'resonance'. ${ }^{31}$ An interpretation of an issue according to the agenda of a particular organisation is communicated via the media, through personal contacts or other means, and a number of people recognise (part of) these views as being of personal concern to them. If this number is high enough, the organisation can increase its legitimisation.

For the survival of any intermediary organisation, resonance with a specific constituency is mandatory. If organisations loose this 'constitutional' resonance, a loss of membership and political impact will entail.

Established interest representation may rely on the ability to mobilise smaller, highly specific publics. In more 'traditional' conflicts such as those over wages or the closure of a factory, resonance with the respective specific public is sufficient. ${ }^{32}$ Such conflicts are often ritualised and follow wellestablished rules, the constituency is more homogenous and material interests usually play a greater role. Resonance with established interests involving institutionalised organisations puts a stronger demand on the regulatory system, so it is sufficient for such organisations to be in resonance with their specific public only.

In contrast, new organisations such as NGOs must seek legitimisation by a relatively large part of the general public. They have a double disadvantage: on the one hand, they must be in resonance with a large representational field or specific public in order to exert influence and to increase legitimisation; the smaller the constituency is the more important it is to transgress its narrow boundaries. On the other hand, interest representation in 'new' conflicts such as those over environmental issues often build less on common material interests and more on shared world-views, and resonance is more difficult to achieve and to stabilise.

31 Both the term 'gate' and 'resonance' have counterparts in the terminology of Niklas Luhmann. In his systems theory, social systems (as systems in general) usually are self-referential, they only deal with internal relations and they are closed vis-à-vis their environment. The process Luhmann calls 'resonance' refers to an irritation of the system through external developments, i. e. events within the respective environment, with the result that the system deals with them (Luhmann 1986, pp.40f). Systems can only perceive developments in the environment which resonate with the system. Whether or not a system resonates depends on the coincidence between the internal structures of the system and those of the external system. Resonance is thus a mechanism that allows a system to react to triggers from outside. The term 'gate' in our model is closely related to the term 'difference' in Luhmann's terminology. Although the Gate/Resonance Model builds upon elements of Luhmann's theoretical thinking, it sets out to analyse parts of the power play between society and the political system and thus covers different aspects (see Luhmann 2000).

32 For example, farmers demonstrating and dumping fruit or professional drivers deliberately choking the traffic with their lorries are powerful enough to put politicians under considerable stress. The same is the case with trade union members in employment conflicts. For companies exerting pressure is even easier, since they can, if large enough, simply threaten to move abroad factories and, hence, jobs and tax revenues. 
For intermediary organisations that lack established channels to policy, i. e. that do not meet the requirements of the gate, eliciting resonance provides an opportunity to influence decision making. As a reaction, institutionalised intermediary organisations with established channels to regulatory institutions, too, may choose to go for public resonance in order to promote their constituencies interests more effectively. ${ }^{33}$

The Social Amplification of Risk approach (Kasperson 1992) states that institutions and organisations being "nodes" of risk amplification observe their environment and try to find topics which enable them to bring their agenda in concordance with public or published opinions. Following this approach, we can say that interest representing organisations try to establish themselves, in a bottomup strategy, as advocates of public interests if the publicly accepted interpretation of a particular issue fits their agenda. Public debates reveal argumentation patterns that intermediary organisations may take up and convey to political institutions. ${ }^{34}$ If an existing public debate is not adequately reflected by the political institutions, new intermediary organisations representing 'orphan' interests may arise. ${ }^{35}$ In contrast, the top-down strategy is to 'invent' a topic in the expectation that a larger part of the public will accept it as something of general interest. Like in a market process, different providers offer narratives, interpretations and facts, which parts of the public will accept or reject.

In practice, both strategies are hard to distinguish. Intermediary organisations can exploit almost everything by re-interpreting events to better fit their agenda. As suppliers and communicators of interests they are issue entrepreneurs. Facts and interpretations are offered to different specific publics and representational fields in order to elicit resonance. Such 'probing' is a trial and error game: organisations monitor, filter and communicate internally and externally what happens in their environment and what they deem relevant according to their specific interests. They also observe whether their communication activities succeed or fail to elicit resonance with the public. Every successful interest-representing organisation explicitly or implicitly, but continually updates its interpretations and at the same time, and in a dialectic process, raise awareness for them among relevant publics.

\subsubsection{Mobilisation}

Actors or organisations with specific interests elicit resonance in parts of the public via the media. For example, they organise events such as demonstrations and spectacular happenings that are able to pass the media's filters of topics to be covered. Resonance induced by information originating from a particular interest representing organisation can in principle enhance the latter's performance to influence regulatory decisions while, in a positive feedback, increasing media consumption. The media communicate with their consumers through a probing process that is complimentary to the one intermediary organisations perform on their specific publics: newspapers approach their readership with a variety of issues in order to find the right 'blockbuster'.

33 An example is the splendid performance of the Swiss scientific community in turning down the Swiss antibiotech 'Genschutz' referendum.

34 This is, or should be, the task of political parties, which have to make sure that the political elite does not detach from what goes on in the public. Most parties do not convey single issue but try to integrate many. For doing so, they need filter mechanisms to select public concerns as discussed in the political arena. Not only political parties provide a filter function, but also NGOs. However, their high integration requirement makes parties slower in reaction and more conservative.

35 An example is the development of environmental NGOs and subsequently of green parties during the 1970s and 1980s, while the existing institutions and parties failed to appropriately convey the unease over risks and to timely enough mitigate environmental conflicts. 
Many probing attempts fail; others find only limited resonance with the public, for example if there is only a small representational field holding compatible views or one or a few specific publics with certain special interests. Media campaigns must find out what consumers want, while operating under considerable constraints concerning the choice of topics. It depends on the skill of the journalist to sense 'where the story is'. This may lead to creating stories that keep the consumers satisfied and, at the same time, influence the opinion climate with respect to future consumer preferences.

In case a probing attempt is successful, a vivid resonance is induced between, for example, a tab$\operatorname{loid}^{36}$ and some representational fields within the public. They may overlap with several specific publics, and the resonance may spread into larger parts of the general public if the issue is salient and the interpretations given fit widely held preferences. Resonance with different publics is made possible because the media's internal structure comprises different fields, corresponding to related but different interests and representational fields in the public.

This exerts pressure on other media to follow those that already have a role in the upcoming mobilisation. ${ }^{37}$ It becomes increasingly difficult even for those newspapers that usually strive for high quality coverage not to join their tabloid counterparts. If an issue has reached a certain level of salience, it can only be ignored at the cost of losses in circulation. To avoid this, other media will join the bandwagon. As the media report on an obviously salient issue, they take part in and, thereby, feed mobilisation while also mirroring it.

Under mobilisation, activated people by and large endorse the demands of a particular group and eventually carry on the message in different forms of social communication. Via mobilisation, resonance between the media, intermediary organisations representing interests and various specific publics and representational fields can generate pressure on the regulatory system and eventually render the gate function obsolete. While the regulatory system therefore tries to avoid non-intended mobilisation, media reporting extensively try to elicit attention and to establish a positive feedback.

Whether there is mobilisation or not is a matter of how actors perceive a situation; hence, it is subject to many actors with different interests agreeing that there is mobilisation. As such, it is a matter of social construction. The tacit agreement about high salience and great interest in the public as mirrored by the media can build up considerable political steam, especially if tabloids or broadcasts are involved that political actors consider powerful. In order to become politically relevant, however, mobilisation must be considered strong enough to pass the gate and overcome institutional resistance. Whether this 'really' is the case does not matter as long as regulators think that mobilisation might indeed flood the gate, and they behave accordingly.

\subsubsection{Policy Change through Mobilisation}

The punctuated equilibrium model of Baumgartner and Jones (1993) describes what happens in such a case. According to these authors, long phases of stability or equilibrium in policy-making alternate with phases of change brought about by interactions of policy subsystems together with their reflection in the media. During the phase of equilibrium, policy is made in the 'normal' mode, heavily depending on experts, where many issues are dealt with at the same time ('in parallel'). High salience of an issue may induce instability, which renders the policy system open to criticism

36 Media succeeding to mobilise the public not necessarily brought up the issue for the first time. In many conflicts, the quality press has been more important than tabloids to raise an issue. Particularly in conflicts on (complicated) technology, tabloids not necessarily keep hunting the quality press.

37 This is illustrated by the case of the British researcher Arpad Pusztai, who announced preliminary results in television that seemed to indicate a negative impact of genetic manipulated potatoes on rat intestines, which was immediately taken up by the tabloid press. 
and provides access to the agenda setting process. In times of instability and agenda access, the system faces an overload and switches to 'serial processing', where only one or a few issues of highest salience get to the regulators' attention. New participants become involved, and the restructuring of a policy subsystem may ensue, which can have long-lasting effects. Even when the issue is low in salience again, existing governing images and institutions may be replaced, and those groups that had a main role in triggering rapid change will frame the new policy in the future.

In the words of our model, enhanced issue salience and ensuing pressure lead to a transition. In the normal mode, political negotiations are restricted to a closed shop where institutionalised organisations and regulatory institutions, through the system of gate and detectors, decide over the access to regulatory decisions. Established intermediary organisations only need to sufficiently resonate with political institutions, i. e. to apply those resources that allow them to communicate 'on a common wavelength'. For such resonance, power through established access and passive legitimisation are adequate.

Intermediary organisations lacking such resources are dependent on finding issues and presenting them in a way that would lead to mobilisation. Mobilisation can deeply affect established interest representing structures and networks. Under pressure, the 'normal' mode of established interest equilibrium, where the gate and the detectors work properly, is turned into an emergency mode of action where selective function is lost. Access to the agenda-setting process then is open, which leads to a disadvantage for institutionalised organisations representing established interests in favour of organisations representing 'newer', less established interests. ${ }^{38}$ As a result, the regulatory institution gets 'flooded' by non-canonical arguments and the most salient issues dominate the agenda. Eventually, new pieces of regulation are issued that would follow arguments formerly not considered relevant or taken seriously.

Several factors can punctuate a regulatory equilibrium. Obviously, the moving of the issue field brings about change through new aspects acquiring political salience. Consequently, new players emerging disturb the established network. Sometimes a regulatory institution itself triggers destabilisation in an attempt to extend its power through a politically risky event, provoking retaliation from other regulatory institutions and tearing apart old established networks. The most important ingredient, however, is public mobilisation providing access to the regulatory system for new arguments and interests. Other groups and organisations jump on the bandwagon, as they exploit the momentum of mobilisation while adding to it. The new combination of actors may build up ever more pressure sufficient to render the gate obsolete and the detectors dysfunctional.

As this threatens the institutional autonomy and the status quo, regulatory institutions by all means try to avoid such a situation. However, the threat of mobilisation alone can short-circuit the normal decision-making process by eliciting early warning detector activity. For the regulatory system in order not to be forced from the normal to the emergency mode, it is necessary to notice any indication of a pending mobilisation in order to issue a precautionary regulatory reaction.

Not only the regulatory system but also institutionalised intermediary organisations representing established interest react to mobilisation if their power is questioned. They too will try to calm down mobilisation in favour of the new interests and, conversely, mobilise public support for their interests in order to retain their influence. ${ }^{39}$ In other words, if an incidence of mobilisation is recognised as being successfully and provides legitimisation to a particular actor or group of actors, a mobilisation contest will result.

38 Austrian NGOs forged strategic links with the biggest tabloid newspaper in the campaign on the anti-biotech peoples' initiative at mutual benefit.

39 In this they do not differ from political parties. 


\subsection{The Model at Work}

In order to see the model at work, we apply it in the following to a topical technology conflict. We take as an example the debate on agricultural biotechnology as it has developed in several European countries to show how the elements described act together.

Since its development in the early 1970s, biotechnology has been discussed in terms of scientific risk. Initially, the problem, as defined by scientists, was a possible health risk associated with working in laboratories, hence, the issue field then contained little more than laboratory safety. Economic promises soon appeared and were a reference point for further developments to come. The first phase of regulatory activities thus erected a gate that was open only for arguments framed by scientific and economic issues and prevented the regulatory system from discussing more general political questions.

When in the 1980s biotechnology left the scientific labs and became applied in different fields, the emerging public discourse on biotechnology exceeded the scientific risk discourse dominant and unquestioned in the 1970s. New actors appeared, bringing in new topics, broadening the debate on biotechnology (Torgersen/Hampel et al. forthcoming) not only with respect to medical applications but also to agricultural biotechnology. Consequently, the issue field underwent a rapid development, and topics other than laboratory safety became salient.

Despite the move of the issue field, experts from science and industry representing the interests of well-established institutions were still successful in restricting the criteria of the regulatory gate to those that fit the established scientific risk concept. The reason for this was partly that, in the Eighties, most regulatory institutions " detectors were susceptible only for arguments pertaining to scientific issues, risks and increasingly also for economic issues including competitiveness. There were hardly any discrepancies between the criteria for uptake by the detectors and the determinants of the gate.

Since biotechnology is a cross-sectional issue, developments also influenced other issue fields. For example, recombinant DNA methods moved the issue field of agricultural plant breeding into a new domain. However, the gate for this field had never acknowledged risk to constitute an 'allowed' category of arguments. With new methods arriving for which 'risk' was a gate category, a tension arose. Environmental and health risk arguments demanded to be heard also in the regulatory discourse about plant breeding and commercial agriculture.

Consequently, organised interests having long been criticising the path of industrial agriculture applied risk arguments stemming from the biotechnology debate to promote their sake, hoping that they would pass the gate. As a consequence, the emerging regulatory debate focussed on risk. In contrast, the social debate was much broader. Plant breeding appeared no longer as something that only traditional high-yield agriculture should deal with. Rather, a wider range of issues was included into the field's focus, like environmental protection and patent issues. The issue field moved on, and the question of agricultural biotechnology, or of genetically modified food, became a proxy for the relation to the countryside, to nature and even to general aspects of modernity (Gaskell et al. 1998). In this way, linking the issue fields of biotechnology and agriculture, technical risk was a major entry point for the political discussion of agricultural biotechnology in Europe, if not of industrialised agriculture as such.

What actually reached the regulatory system was much more focussed, and the questions put on the agenda were confined by the determinants of the biotechnology gate. There were only few issues considered relevant for example according to the EU Directive 90/220 regulating deliberate releases and the placing on the market of genetically modified products. Officially, only questions of scientifically demonstrable risks to human health or the natural environment were allowed to pass the regulatory gate. Both national and European regulatory institutions rejected anything else as irrelevant and beyond the scope irrespective of the fact that there was a whole range of new issues within the reach of the issue field. The only possibility to give them a voice was to frame them in a 
way that would pass the gate. Hence, a new interest only had a chance to be taken up if the promoters of this interest succeeded to find an aspect that could be framed as an issue of risk to human health or the environment.

Unofficially, regulatory institutions had taken notice through information conveyed by their detectors - which provided a contradictory picture as to the salience of the new issues, and generally reinforced the respective institutional bias. It underestimated the potential political hazard for the respective institution, not the least because influential organisations representing established interests like trade unions, farmers ' associations and industry were generally in favour of biotechnology. In contrast, 'new' intermediary organisations that opposed biotechnology such as NGOs representing interests of the environment or consumers mostly lacked direct access to the regulatory system. They had failed to stop biotechnology by means of officially acknowledged risk arguments able to pass the gate, so they applied a strategy to de-legitimise the political system's coverage of the issue field by means of mobilisation.

To this end, they subsequently mobilised their constituency, and since in many cases this constituency was not big enough to exert political pressure, they seeked to attract the attention of relevant interest fields. Eventually, they approached also representational fields holding 'green' views and finally parts of the general public.

As a second strategy, they also tried to reframe the risk discourse in order to re-define the determinants of the gate. While risk as defined by scientific evidence was still predominant in the regulatory discourse, NGOs adopted new concepts of risk (see Beck 1986) which allowed them to address uncertainty. The absence of evidence was no longer sufficient to show that there were no (or negligible) risk, rather, it became necessary to provide, if not evidence, at least strong arguments for the absence of risks.

For the regulatory discourse, NGOs modified the political question of the future of agricultural development into a question of consumer safety and individual health protection and provided interpretations of consumers as guinea pigs for a technological development where the further outcome could not be overseen. Attempts of regulators, scientists and industry to keep the interpretation of risk according to technological risk assessment, i. e. according to the old gate determinants, totally failed. Arguments of NGOs succeeded to resonate with the public as illustrated by surveys on public perception of agricultural biotechnology (BEP 1997, Durant/Bauer/Gaskell 1998, Gaskell/Bauer 2001). Not surprisingly, technical risk assessment as applied by regulators played little role in the public discourse on agricultural biotechnology (Hampel/Renn, 1999, Wagner et al., 2001).

The reshaping of the biotechnology discourse by means of public mobilisation would not have been possible without the media. The rising profile of agricultural biotechnology within a medium could be judged according to its coverage in different sections, addressing different representational fields. While the issue first appeared in the science or business sections, it eventually moved on to the general policy section the moment it got hot. Then, a bandwagon effect led to broad coverage of the issue over a period of time irrespective of whether it was in a quality newspaper or a tabloid.

The halo of established interests and regulatory institutions tried to establish counter strategies. They sought ways to de-mobilise the public and get the issue out of media headlines. However, since in the meantime a heavy resonance had established between NGOs, their constituencies and interest fields, this was far from being easy. Moreover, there was resonance between tabloids, NGOs and a wide variety of organisations, interest groups and even representational fields that rendered de-mobilising attempts futile. Instead, pressure on the regulatory system increased.

The gates originally designed to keep outside everything that could not be framed as a risk could no longer exert their selective function. Informal information indicated hazards for the regulatory autonomy, but it was too late to act proactively. Because public pressure was high, the regulatory system got flooded with demands to take into account a wide variety of aspects and arguments, often stemming from actors that were hitherto not considered relevant. 
As long as media probing attempts were even moderately successful, regulatory institutions stayed in the 'normal' mode of operation processing issues in a business-as-usual way. When the public became mobilised, the normal mode of dealing with the problem was no longer feasible. Mobilisation events entailed a shift to the emergency mode: a particular issue, biotechnology, got to the fore and was treated with priority, often absorbing large parts of the institution's working capacity. Thus, resonance between media and parts of the public affected regulatory decisions simply by occupying the processing capacity of one or several institutions. Under such conditions, solutions were taken up that had been at hand for a time but never been considered relevant. ${ }^{40}$ This impaired the overwhelming influence of established interests and the institutionalised intermediary organisations' ability to determine policy contents.

Institutions within the political system have an interest to retain autonomy and function in a business-as-usual way, so they developed strategies to counter-act. Since mobilisation is time-dependent and often wane after a climax, the main problem was to survive the storm. An important aspect was to gain time. Another strategy was to de-mobilise the interest fields by channelling the protest into processes. For example in France, participatory measures like a consensus conference offered possibilities to contain the protest and, since it took a long time to prepare, there was a considerable amount of time gained. Other strategies were aimed at voicing rhetorical compromises oriented for public consumption. Such compromises conveyed the impression that the regulatory institution (or even the system as a whole) had grown much more open. ${ }^{41}$ For example, a strategy of institutional learning was to re-tune the gate to take into account ethical considerations. In most European countries, ethics committees were established to evaluate the consequences of modern biotechnology.

As pressure decreased due to such activities, the institutions could return to the normal mode of processing incoming issues. The now modified gate regained its function. However, the storm had moved the issue field in a different direction. The regulatory system and the intermediary institutions could not neglect such a change. Information taken up informally conveyed a different picture of the issue, resulting in a change in the political content. New actors had entered the scene exploiting the situation when the gate was dysfunctional and the system open for their arguments; new interests had acquired a position that could no longer be denied. Changes could not be avoided and institutions needed to adapt. A new setting was established as part of the institution's learning, which would determine the various actors' positions in conflicts to come.

40 When in 1999 public protests against agricultural biotechnology over large parts of the EU had absorbed the regulatory capacity of the DG XI of the European Commission, they refused to accept new applications for marketing permissions. By default, they issued a temporary moratorium that had been on the list of possible solutions for a decade, but never had been considered relevant. This situation opened a window of opportunity for a policy shift, which found its expression in the long overdue revision of the Directive $90 / 220$. The measures taken up were far from new, but the time had come for a formal implementation of formerly rejected policy elements (Levidow et al. 2000).

41 For example, the European Commission's preoccupation with the Precautionary Principle might be understood in this way. 


\section{Final Remarks}

The gate/resonance model provides an analytical frame to describe what happened in this particular conflict. We believe that it is general enough to help understanding other cases, too, although it is more of a middle-range model that is intended as feed for further thoughts rather than being a fully elaborated theory.

Further work will be necessary especially to integrate aspects such as the role of science, business and other sectors (or sub-systems) into the model. Also, the role of state institutions may appear somewhat static. We are aware of that together with political parties they, too, are active participants in the game of eliciting attention in a society that is ever more dependent on media action to the degree that media coverage develops into a major determinant for policy. However, we believe that the conceptualisations already provided in the gate/resonance model will contribute to a better understanding not only of past technology conflicts but also of emerging controversies yet to come.

\section{References}

ATKINSON, M. M., COLEMAN, W. D. (1992): Policy networks, policy communities and the problem of governance. In: Governance. Vol. 3, p. 115-137.

BAUER, M. W., KOHRING, M., ALlAnsDOTTIR, A., GUTTELING, J. (2001): The dramatisation of biotechnology in elite mass media. In: Biotechnology 1996-2000 - the years of controversy. London, Science Museum Press.

BAUMGARTNER, F. R., JONES, B. D. (1993): Agendas and instability in American politics. Chicago, University of Chicago Press.

DOUGLAS, M., WILDAVSKY, A. (1982): Risk and Culture, Berkeley, University of California Press.

GASKELL, G., BAUER, M. W., DURANT, J. (1998): The representation of biotechnology: policy, media and public perception. In: Durant, J., Bauer, M. W., Gaskell, G., (eds.), Biotechnology in the public sphere. A European sourcebook. London, Science Museum Press.

GASKELL, G., BAUER, M. W. (2001): Biotechnology in the years of controversy - a social scientific perspective. In: Biotechnology 1996-2000 - the years of controversy. London, Science Museum Press.

HAMPEL, J., RENN, O. (1999): Gentechnik in der Öffentlichkeit. Wahrnehmung und Bewertung einer umstrittenen Technologie. Frankfurt, Campus. (a shortened english version of the book is published in: New Genetics and Society, vol. 19, no. 3, Dec. 2000).

JASANOFF, S. (1990): The Fifth Branch. Science advisers as policymakers. Harvard, Cambridge/ New York.

KASPERSON, R. E. (1992): The Social Amplification of Risk: Progress in Developing an Integrative Framework. In: S. Krimsky, D: Golding (eds.): Social Theories of Risk. Praeger, Westport, p. 153-178.

LUHMANN, N. (1986): Ökologische Kommunikation. Kann die moderne Gesellschaft sich auf ökologische Gefährdungen einstellen? Opladen, Westdeutscher Verlag. 
LUHMANN, N. (2000): Die Politik der Gesellschaft. Frankfurt, suhrkamp.

MAYNTZ, R. (1993): Policy-Netzwerke und die Logik von Verhandlungssystemen. In: Héritier, A. (ed.): Policy-Analyse. Kritik und Neuorientierung. Politische Vierteljahresschrift, special issue 24/1993. Opladen, Westdeutscher Verlag.

McCOMBS, M. E., SHAW, D. L.: The agenda-setting function of mass media. In: Public Opinion Quaterly, vol 36(1972), p. 176-187.

MILLSTONE, E., van ZWANENBERG, P., MARRIS, C., LEVIDOW, L., TORGERSEN, H., The scientific basis of applying the Precautionary Principle in biotechnology-related potential trade conflicts. ESTO final report, forthcoming.

NOWOTNY, H., SCOTT, P., GIBBONS, M. (2001): Re-thinking science. Knowledge and the public in an age of uncertainty. Cambridge/Oxford, Polity Press/Blackwell.

PETERS, H. P. (2000): The Committed are hard to persuade. Recipients' thoughts during exposure to newspaper and TV stories on genetic engineering and their effect on attitudes. In: New Genetics and Society, vol. 19, no. 3, Dec. 2000, p. 365-382.

RENN, O. (1992): The social arena concept of risk debates. In: S. Krimsky, D. Golding (eds.): Social Theories of Risk. Westport/London, Praeger, p.179-196.

SCHARPF, F.W. (1993): Positive und negative Koordination in Verhandlungssystemen. In: Héritier, A. (ed.): Policy-Analyse. Kritik und Neuorientierung. Politische Vierteljahresschrift, special issue 24/1993. Opladen, Westdeutscher Verlag.

SCHENK, M. (1987): Medienwirkungsforschung. Tübingen, J.C.B. Mohr.

SLOVIC, P., FISCHHOFF, B., LICHTENSTEIN, S. (1985): Characterizing perceived risk. In: Kates, R. W., Hohenemser, C., Kasperson, J. X. (eds.): Perilous progress: managing the hazards of technology. Boulder (Co), Westview.

STREECK, W. (1994): Korporatismus in Deutschland. Zwischen Nationalstaat und Europäischer Union. Frankfurt/New York, Campus.

TORGERSEN, H., SEIFERT, F. (2000): Precautionary Blockage of Agricultural Biotechnology, J. Risk Research 3, 3, pp. 209-217.

TORGERSEN, H., HAMPEL, J. et. al., forthcoming: European Biotechnology Debate and Regulation: The First 25 Years. In: Durant, J., Bauer, M., Gaskell, G. (eds.): European Debates on Biotechnology: Dimensions of Public Concern. London, Cambridge University Press.

WAGNER, W. KRONBERGER, N. (2001): 'Killer tomatoes! Collective symbolic coping with biotechnology', in Deaux, K. and Philogene, G. (eds.), Representations of the Social. Oxford, Blackwell. 


\section{Previously published manu:scripts}

ITA-0I-0I Gunther Tichy, Walter Peissl (12/2001): Beeinträchtigung der Privatsphäre in der Informationsgesellschaft. <http://www.oeaw.ac.at/ita/pdf/ita_01_01.pdf>

ITA-0I-02 Georg Aichholzer(12/2001): Delphi Austria: An Example of Tailoring Foresight to the Needs of a Small Country. <http://www.oeaw.ac.at/ita/pdf/ita_01_02.pdf>

ITA-0I-03 Helge Torgersen, Jürgen Hampel (12/2001): The Gate-Resonance Model: The Interface of Policy, Media and the Public in Technology Conflicts.

$<$ http://www.oeaw.ac.at/ita/pdf/ita_01_03.pdf>

ITA-02-0I Georg Aichholzer (01/2002): Das ExpertInnen-Delphi: Methodische Grundlagen und Anwendungsfeld ,Technology Foresight“.

<http://www.oeaw.ac.at/ita/pdf/ita_02_01.pdf>

ITA-02-02 Walter Peissl (01/2002): Surveillance and Security - A Dodgy Relationship. <http://www.oeaw.ac.at/ita/pdf/ita_02_02.pdf> 